Research Article

\title{
Perception on Road Traffic Injuries and Safety in New Delhi: A Qualitative Study among Victims, their Attendants and General Public
}

\author{
Nalini Tripathi', Harpreet Kaur $^{2}$, Aparnavi ${ }^{3}$, Surabhi Sethi ${ }^{4}$, Bontha V Babu ${ }^{5}$, Jugal Kishore ${ }^{6}$ \\ ${ }^{1}$ Scientist C ICMR Project, VMMC \& Safdarjung Hospital, New Delhi. \\ ${ }^{3} J u n i o r$ Resident, Post Graduate, ${ }^{2}$ Department of Community Medicine, VMMC \& Safdarjung Hospital, New Delhi. \\ ${ }^{4}$ Assistant Professor, Department of Community Medicine, NDMC Medical College \& Hindu Rao Hospital, Delhi. \\ ${ }^{5}$ Scientist - G \& Head, Division of Socio-Behavioural \& Health Systems Research, Indian Council of Medical Research, New Delhi. \\ ${ }^{6}$ Director Professor \& Head, Department of Community Medicine, VMMC \& Safdarjung Hospital, New Delhi. \\ DOI: https://doi.org/10.24321/2454.325X.201919
}

I $\mathbf{N}$ F $\mathbf{O}$

Corresponding Author:

Jugal Kishore, Department of Community Medicine, VMMC \& Safdarjung Hospital, New Delhi.

E-mail Id:

drjugalkishore@gmail.com

Orcid Id:

https://orcid.org/0000-0001-6246-5880

How to cite this article:

Tripathi N, Kaur H, Aparnavi, Sethi S, Babu BV, Kishore J. Perception on Road Traffic Injuries and Safety in New Delhi: A Qualitative Study among Victims, their Attendants and General Public. Int J Preven Curat Comm Med 2019; 5(3): 18-23.

Date of Submission: 2019-12-06

Date of Acceptance: 2019-11-20

\section{$\begin{array}{lllllllllllll}\mathbf{A} & \mathbf{B} & \mathbf{S} & \mathbf{T} & \mathbf{R} & \mathbf{A} & \mathbf{C} & \mathbf{T}\end{array}$}

Introduction: Road Traffic Injuries (RTI) are one of the threats to public health and development globally and contribute to causing deaths, disabilities, grief, loss of productivity and material damages. Hence, enquiries on why road traffic injuries are increasing in number and how they can be controlled are to be made.

Objective: To understand the perceptions of victims, their attendants and general public on road traffic injuries and safety.

Methodology: A study was carried out among adult victims of RTI admitted in a tertiary care hospital, their attendants and general public living in an urban settlement in New Delhi. Qualitative data on perspectives about road traffic injuries were collected by focus group discussions (FGDs) and data was analysed.

Result: A total of 5 FGDs were conducted involving 32 participants, aged 18-92 years. Apart from non-human factors such as poor road infrastructure and road congestion; distracted driving, urgency and excitement in behaviour, aggression and carelessness in attitude, emerged as major reasons for road traffic injuries.

Conclusion: The study reinforced that in addition to road traffic environments, changes in attitudes and behaviour especially in the young require a combined effort from the parents, schools and media and novel ideas should be used to bring behavioural change especially in the youth.

Keywords: FGD, Road Traffic Injuries, Road Conditions, Driving Behavior 


\section{Introduction}

Globally, road traffic injuries are a cause of significant economic losses to individuals, their families, and nations. Every year approximately 1.35 million people lose their lives as a result of road traffic injuiries. It is now the leading cause of death in children and young adults. More than half of all road traffic deaths are among vulnerable road users: pedestrians, cyclists and motorcyclists. ${ }^{1}$

In India, a total of 4,64,910 road accidents have been reported by States and Union Territories (UTs) in 2017, claiming 1,47,913 lives and causing injuries to 4,70,975 persons. ${ }^{2}$ Among vehicle categories involved in road accidents, two-wheelers accounted for the highest share (33.9\%) in total accidents and fatalities (29.8\%) in 2017. A total of 48,746 road users on two-wheelers lost their lives to road accidents and constitute a single largest road user category in the number of road accident deaths in 2017. Out of this, $73.8 \%$ did not wear helmets. The share of two-wheeler riders in total fatality has been highest (33\%) in 2017, and fatal road accident victims largely constitute young people in productive age groups. ${ }^{2}$

Young adults in the age group of 18 - 45 years accounted for $72.1 \%$ of victims during $2017 .{ }^{2}$ Traffic environment factors (non-human) such as inadequate road infrastructure, overburdened or overcapacity hauling of public and transport vehicles, poor maintenance of the vehicles are extensively studied and measures for road safety have been proposed and implemented. Human factors contribute significantly to the increasing number of road accidents in India. Hurry and error in judgment often lead to major accidents. Reckless driving, over speeding, decline to follow traffic rules, and drunken driving are the main reasons for road accidents. ${ }^{3}$

A considerable number of quantitative studies have been conducted to understand the various aspects of road traffic accidents and safety. However, there is lack of qualitative enquiries on people's perceptions on road safety and hazards, their opinions regarding traffic rules and regulations, behaviours and attitudes of drivers and public on encountering road traffic-related injuries as well as the opinions about methods that would prevent road traffic accidents. These kind of enquiries will be useful in developing studies to bring behavioural changes and later to implement public health interventions to mitigate the burden of road traffic injuries. The present study explores the perception of the victims, their attendants and general public on the road traffic accident and safety.

\section{Methodology}

A qualitative study was conducted in a tertiary care hopital (Vardhman Mahavir Medical College and Safdarjung Hospital) and a community catered by an Urban Health
Training Centre, in New Delhi. The study was conducted over a period of 2 months in the year of 2019.

\section{Study Participants}

A total of five FGDs including a heterogenous population were conducted. The participants of the FGDs were Road Traffic Accident (RTA) victims admitted in the hospital, their attendants, young and elderly adults, ambulance drivers and post graduate students. The hospital victims and their attendants were approached in the wards, the young and elderly males were approached from the community of an urban village of Delhi. The ambulance drivers under the Emergency department of a tertiary hospital were selected. The post graduate students were approached in the Department of Community Medicine at Vardhman Mahavir Medical College.

\section{Study Procedure}

The research team comprised of three of the authors, fluent in the local language Hindi. The moderators had several prior experiences of conducting FGDs and qualitative data collection. The domains of enquiry covered by group discussions were: perceptions regarding causes of RTA, existing traffic rules and regulations, behaviour and attitudes of drivers, the attitude of passersby on accident site and suggestions regarding prevention of RTA. The topics were developed in English and translated to Hindi, the local language of Delhi. They were pre-tested for their relevance, suitability and ease to be carried out in the community.

Verbal informed consent was obtained from all participants. Focus group discussions were conducted in Hindi, audiotaped and handwritten verbatim notes were supplemented with transcripts of audio recordings and then translated to English. The participants' actions, gestures and emotions that could not be captured on audio tape were noted. The average time taken in conducting FGDs was 50-60 minutes. The focus group sessions followed the following pattern: welcome and self-introduction, explanation of the study and consent taking, discussion, de-briefing of the discussion, allowing participants, if they have anything to say and appreciation for participation. At the end of each FGD, notes on impressions and observations, and highlights of each FGD were compiled and examined for new information and repetitions.

\section{Data Management and Analysis}

All the FGDs were transcribed into Hindi while listening to the audio-tapes and simultaneously checking with the notes taken during discussion. All these Hindi transcripts were translated into English. Translations were checked for linguistic reliability and correctness in translation.

The data were entered into a word processor. Later the data were reorganized under different themes based on the topic guide. Under each theme, several codes were identified 
and relevant quotes were kept under each code. Inferences were drawn collectively by careful reading of the text under each code. These data were read and re-read to check the appropriateness of the inferences drawn.

\section{Ethical Considerations}

The project protocol is the part of ICMR National Task force on Road Traffic Injuries Surveillance which was approved by the Institutional Ethical Committee. All participants were informed individually about the study objectives and all the participant gave their consent for interviewing and recording prior to participation. No incentives were given to the participants. The data was used only for research purpose and identity of participants was kept anonymous.

\section{Result}

The participants of the FGDs were Road Traffic Accident (RTA) victims admitted in the hospital, their attendants, young and elderly adults, ambulance drivers and post graduate students. The age range of the participants was 18-92 years.

Out of 32 participants, 5 were women and 27 were men. The men were involved in salaried jobs, skilled works, small business, students or retired. The women were either homemakers or students (Table 1).
They believed that the reasons behind people not complying to use of helmets were discomfort, no intention to wear protective gear, concern regarding their style and looks, and reduction in their pride.

"Logon ko lagta hai, helmet lagane se unki shaan ghat jayegi" (people think that by using helmets they will lose their pride).

\section{Compliance to Traffic Rules and Regulations}

The majority believed that the urgency in behaviour and a careless attitude are the main reasons for violatation of traffic rules. They pointed out that young drivers lack the fear of consequences, felt a sense of autonomy while driving, have a thrill-seeking behaviour, are aggressive and give into peer pressure. This results in their aversion to follow suggestions by the elder members regarding safe driving. One of the participants stated.

"Log apni marzi ke hisaab se gaadi chalate hai, logon ko lagta hai ki humara kuch bura ho hi nahi sakta" (people drive as they like and believe that nothing bad can happen to them).

"Ladke chahte hai meri gadi sabse tez chalni chahiye" (boys desire that their vehicle should be the fastest).

Some participants believed that lack of heavy fines, ease of

Table I.Age range and gender distribution of study participants

\begin{tabular}{|c|c|c|c|c|c|}
\hline \multirow{2}{*}{ S.No. } & \multicolumn{5}{|c|}{ Participants (n =32) } \\
\cline { 2 - 6 } & $\begin{array}{c}\text { Victims and their } \\
\text { attendants (6) }\end{array}$ & Young adults (6) & Elderly adults (8) & $\begin{array}{c}\text { Ambulance } \\
\text { drivers (6) }\end{array}$ & $\begin{array}{c}\text { Postgraduate } \\
\text { students (6) }\end{array}$ \\
\hline Male & 3 & 6 & 8 & 6 & 4 \\
\hline Female & 3 & 0 & 0 & 0 & 2 \\
\hline Age range (yr) & $27-49$ & $18-21$ & $65-92$ & $30-55$ & $25-28$ \\
\hline
\end{tabular}

Core themes identified for analysis were: (a) causes of road traffic accidents, (b) compliance to traffic rules and regulation, (c) driving behaviour of motorcyclists, (d) attitude of passersby at the accident site and (e) prevention of road traffic accidents.

\section{Perceived Causes of Road Traffic Accidents}

Road congestion, poor road conditions, distracted driving, traffic rules violation (such as over speeding, overtaking, driving on the wrong side of the road, drunk driving, no compliance to helmet and seatbelt use and talking on the phone while driving), mishaps involving overloaded heavy motor vehicles and unsafe pedestrian behavior were reasons for most accidents. One of the participants said, "Itni bheed hai sadko pe" (The roads are very congested). Another stated "Log traffic ke niyamon ka palan nahi karte, log bhaag daud mein rehte hai, unke pass time nahi hota" (People do not follow traffic rules, people are in a hurry and they have no time with them). bribing traffic police and lack of strictness by the authorities in issuing licenses were the cause of people not following existing traffic rules and regulations. One of the participants said.

"Bina test ke license mil jata hai" (Driver licenses are issued without conducting any driving test).

\section{Behavior of Motorcyclists}

Groups believed that motorcyclists have carelessness in their attitude, are aggressive and always in a hurry. Inefficient driving skills and lack of maturity in young riders were also pointed by some. Lack of parental control in underage drivers was pointed out as a reason for such behavior.

"Bache immature hote hai, motorcycles ki demand karte hai, beparwah chalate hai aur maa baap parwah nahi karte" (Young kids are immature, they demand motorcycles, drive carelessly and parents do not care). 


\section{Attitude of Passersby at Accident Site}

There was a difference in opinion on the attitude of passersby at accident site. While some believed that most people hesitate to help due to fear of consequences from police and lack of time and panic situation. This situation was mainly due to lack of awareness regarding "Good Samaritan law". Some group participants believed that most people help due to change in policies and laws. A few pointed out that a new trend of recording videos and clicking pictures of the accident victim instead of helping has emerged.

"Log phone se video lene baith jaate hai, aajkal trend hai ki shooting karte hai par ab rules badal diye hai ki tum agar kisiki madad karogay toh tumpe karyawahi nahi hogi" (People take videos from their phones, but now rules have changed that if you help the victim you will not be prosecuted).

\section{Suggestions Regarding the Prevention of Accidents}

The majority believed that heavy fines along with disqualifying from holding driving license on traffic rules violation, improvement in road safety and related infrastructure, stricter rules for issuing driving license and awareness regarding traffic rules and regulations along with their importance should be given through media, especially social media. Further, groups felt that people should change their behaviour towards safe driving.

"Behaviour mein logon ko sabhar karna chahiye, zyada jaldi nahi honi chahiye, red-light jump nahi karni chahiye" (People should be patient in their behavior, should not have urgency, and should not jump red-light signals).

A few believed that measures such as good parental control over young children and students should be educated regarding safe driving behaviour and social responsibility in schools. Social media can be used to educate masses. They emphasized that people should be made sensitive regarding valuing their lives and also other lives.

"Young bacho ko TV aur school aur whatsapp ke madhyam se jagruk karna chahiye".

(Young children should be made aware using mediums like television and WhatsApp and in schools).

"School basis pe hona chahiye"(Awareness should be given in schools).

\section{Discussion}

The study assessed the perspectives of heterogeneous population groups on RTI and safety. The perception among the people regarding causes of RTA were: Road congestion, poor road conditions, inadequate road infrastructure, distracted driving.Violation of traffic rules such as over speeding, overtaking, driving on the wrong side of the road, drunk driving, non-compliance to safe driving like helmet and seatbelt use and talking on the phone while driving, mishaps involving overloaded heavy motor vehicles and unsafe pedestrian behavior, lack of heavy fines, inconsistent enforcement of traffic policies by police in the form of ease of bribing and lack of strictness by the authorities in issuing licenses. A similar study carried out in the city of Hyderabad elicited factors such as inadequate traffic laws, gaps in enforcement, lack of awareness, lack of political will, poor road engineering, and high-risk road users as threats to road safety. ${ }^{4}$

In the present study use of cell phone has been identified as one of the reasons for RTA. A number of studies regarding above-stated reasons such as over speeding, helmet use behaviour, phone use while driving and pedestrian behaviour have reported the same. ${ }^{3,5-7}$ According to a study in the city of Toronto, using a cellular telephone was associated with a risk of having a motor vehicle collision that was about four times as high as that among the same drivers when they were not using their cellular telephones.8 In a study Klauer et al., among novice drivers in Virginia (USA), dialling or reaching for a cell phone, texting, reaching for an object other than a cell phone, looking at a roadside object such as a vehicle in a previous crash, and eating were all associated with a significantly increased risk of a crash or near-crash. Among experienced drivers, only cell-phone dialling was associated with an increased risk. ${ }^{9}$

In the present study, inefficient driving skills and lack of maturity in young riders were perceived as the reasons for RTA. Similarly, in a study assessing opinions of police officers and the public, the frequently identified causes contributing to young driver accidents were drugs or alcohol, excessive speed, inexperience, and distraction and identified medical conditions and poor eyesight as typical of older driver collisions. Factors such as failure to look properly, loss of control, and failure to judge another person's path or speed were the most frequently recorded factors across drivers' age and gender. ${ }^{10}$

Urgency and excitement in behaviour, aggression and carelessness in attitude were perceived as behavioural causes for road traffic accidents, especially in young male motorcyclists. A study by Taubman-Ben-Ari O in Israel shows that more risky driving was related to higher sensation seeking and trait anger, along with a greater willingness to take risks when driving and a higher tendency to become angry in various traffic situations. ${ }^{11}$

According to a study, compared to calm and composed drivers, short tempered drivers report more triggers for their anger while driving, report more frequent and intense anger, think in more hostile, aggression-oriented ways, express their anger in less constructive and more aggressive ways. They experience more adverse consequences which 
stem from their anger and aggression, engage in more risky behaviour when driving, and experience more of some crash-related conditions. ${ }^{12}$

No fear of consequences, sense of autonomy while driving, sensation-seeking behaviour, aggression among youth, peer pressure, aversion to follow suggestions of elders regarding safe driving were reasons pointed out regarding accidents involving young persons. Studies show that young drivers who reported committing the most road traffic violations were most influenced by their peers in two particular ways: one as a means to attain prestige within their social group and the other by accepting their peers' intervention in their driving. ${ }^{13}$ The perception of risky driving among peers is associated with teens' risky driving. ${ }^{14}$

Inefficient driving skills and lack of maturity in young riders, lack of parental control in underage drivers were perceived reasons for accidents in youth. Drivers who are more mature and have strong positive connections with their parents and peers report safer driving practices. Safe driving is also related to better communication and mutual respect. ${ }^{15}$

A road safety climate created by parents is crucial to the safe road use and driving of their children. ${ }^{16}$ It is also shown that higher risky driving by parents was found to be positively related to higher risky driving by their male offspring. Moreover, parents' own personality, and especially one of the father, was associated with the male young drivers' risky driving. ${ }^{14}$ Perceptions regarding the public reaction to road traffic accidents were: hesitation to help due to fear of consequences from police authorities, and lack of time and panic situation. Reasons for hesitation mainly stem due to lack of awareness regarding Good Samaritan law rules. A new trend of recording videos and clicking pictures of the accident victim instead of helping also emerged, a behaviour that can be explored in future studies.

Opinions regarding prevention of road traffic injuries included heavy fines along with license suspension on traffic rules violation, improvement in road safety and related infrastructure, stricter rules for obtaining a drivers' license and awareness regarding traffic rules and regulations along with their importance given through media especially social media and at school level. Emphasis on respecting and valuing peoples' lives should be inculcated since childhood. In a study, the suggestion of incorporation of road traffic education sessions into school curricula using storybooks as teaching tools was considered beneficial. ${ }^{17}$

Another study that extended these findings to road users within the context of employment in a multi-national company. Inadequate adoption of road safety best practices, dissonance between road safety knowledge and actual practice (both personal and observed), inadequate road infrastructure, inconsistent enforcement of traffic policies by police, and corporate business cost and efficiency strategies which were at odds with road safety, e.g., requiring on-time arrival to work during high traffic times of day were pointed out as challenges to road safety. Potential interventions for better road safety included improvement of safety infrastructure, enforcement of vehicular and driving standards on corporate campus roadways, interactive road safety education, policies that would lessen pressure for work arrival at high-traffic times, improvement of company-provided transportation or car-pooling options, and advocacy efforts targeted to local government. ${ }^{18}$

The methods through which these perceptions regarding road traffic injuries with an emphasis on behaviours and attitudes were identified, can easily be replicated at various educational and workplace locations in different cities and towns. The interpretation of the results of this study should not be generalized but act as a guide towards a local perspective that is important to elicit and understand when planning and enacting road safety interventions. Through this study we aim at understanding the perspective among people regarding RTA to aid in behavioural change in the population by developing interventions in the future that will tackle the mentioned issues.

\section{Limitations of the Study}

The inherent limitation of the study was the differences in the respective participant populations that may have impacted upon the generalisability and the comparability of the results. Thus, the findings cannot be extended to the wider population with a degree of certainty. Research studies in the future should be conducted in urban as well as rural settings across various states enabling implementation of safety strategies which can be advocated at a local, state, national level.

\section{Conclusion}

Peoples' perception regarding road safety and interventions available for implementation in a city like New Delhi where immigration boom due to economic development has increased and motorization leading to increased road traffic accidents emerged from this study. More importantly, this study reinforced that in addition to non human factors, changes in attitudes and behaviour especially in the young and youth, require a combined effort from the parents, schools and media and novel ideas should be identified to bring about behavioural change.

Qualitative enquiries from local people offer an easy and replicable methodology to gain a perspective of urban dwellers for road traffic problems and such studies provide clues on possible future intervention strategies.

\section{Acknowledgement}

The paper is based on the data collected during a national 
task force study, IRIS-India, funded by Indian Council of Medical Research, New Delhi.

\section{Conflict of Interest: None}

\section{References}

1. WHO. Global Status Report on Road Safety 2018. Geneva, WHO. Available from: https://www.who.int/ violence_injury_prevention/road_safety_status/2018/ en/.

2. Road Accidents in India - 2017. morth.nic.in/ road-accidents-india. Available from: http://www. indiaenvironmentportal.org.in/files/file/road\%20 accidents\%20in\%20India\%202017.pdf.

3. Gopalakrishnan S. A Public Health Perspective of Road Traffic Accidents. J Family Med Prim Care 2012; 1(2): 144-150. [DOI: 10.4103/2249-4863.104987/PubMed/ Google Scholar/ ResearchGate].

4. Tetali S, Lakshmi JK, Gupta S, Gururaj G, Wadhwaniya S, Hyder AA. Qualitative study to explore stakeholder perceptions related to road safety in Hyderabad, India. Injury 2013; 44: S17-S23. [DOI: 10.1016/S00201383(13)70208-0/ PubMed/ Google Scholar].

5. Pal R, Ghosh A, Kumar R, Galwankar S, Paul SK, Pal S et al. Public health crisis of road traffic accidents in India: Risk factor assessment and recommendations on prevention on the behalf of the Academy of Family Physicians of India. AFPI Position Paper on Road Safety and Public Health 2019; 8(3): 775-783. Available from: http://www.jfmpc.com/article.asp?issn=2249-4863; ye ar=2019; volume=8;issue=3; spage=775; epage=783; aul ast=Pal [DOI: 10.4103/jfmpc.jfmpc_214_18/PubMed/ Google Scholar].

6. Oviedo-Trespalacios O, Haque MM, King M, Demmel S. Driving behaviour while self-regulating mobile phone interactions: A human-machine system approach. Accid Anal Prev 2018; 118: 253-262. [DOI: 10.1016/J. AAP.2018.03.020/ PubMed/ Google Scholar].

7. Goel R, Jain P, Tiwari G. Correlates of fatality risk of vulnerable road users in Delhi. Accid Anal Prev 2018; 111: 86-93. [DOI: 10.1016/J.AAP.2017.11.023/ PubMed/ Google Scholar].

8. Onald D, Edelmeier AR, Ibshirani OJT. Association Between Cellular-Telephone Calls and Motor vehicle collisions. N Engl J Med 1997; 336(7): 453-458. Available from: https://www.nejm.org/doi/pdf/10.1056/ NEJM199702133360701?articleTools=true. Accessed May 8, 2019. [PubMed/ Google Scholar].

9. Klauer SG, Guo F, Simons-Morton BG, Ouimet MC, Lee SE, Dingus TA. Distracted Driving and Risk of Road Crashes among Novice and Experienced Drivers. N Engl J Med 2014; 370(1): 54-59. Available from: https:// www.nejm.org/doi/10.1056/NEJMsa1204142?url_ ver=Z39.88-2003\&rfr_id=ori\%3Arid\%3Acrossref. org\&rfr_dat=cr_pub\%3Dwww.ncbi.nlm.nih.gov [DOI:
10.1056/NEJMsa1204142/ PubMed/ Google Scholar].

10. Rolison JJ, Regev S, Moutari S, Feeney A. What are the factors that contribute to road accidents? An assessment of law enforcement views, ordinary drivers' opinions, and road accident records. Accid Anal Prev 2018; 115: 11-24. Available from: https://www.sciencedirect. com/science/article/pii/S0001457518300873 [DOI: 10.1016/j.aap.2018.02.025/ PubMed/ Google Scholar].

11. Taubman - Ben-Ari O, Kaplan S, Lotan T, Prato CG. The combined contribution of personality, family traits, and reckless driving intentions to young men's risky driving: What role does anger play? Transp Res Part $F$ Traffic Psychol Behav 2016; 42: 299-306. Available from: https://orbit.dtu.dk/en/publications/the-combinedcontribution-of-personality-family-traits-and-reckle [DOI: 10.1016/J.TRF.2015.10.025/ Google Scholar].

12. Deffenbacher JL, Stephens AN, Sullman MJM. Driving anger as a psychological construct: Twenty years of research using the Driving Anger Scale. Transp Res Part F Traffic Psychol Behav 2016; 42(2): 236-247. Available from: https://www.sciencedirect.com/science/ article/abs/pii/S1369847815001722 [DOI: 10.1016/J. TRF.2015.10.021/ Google Scholar].

13. Weston L, Hellier E. Designing road safety interventions for young drivers - The power of peer influence. Transp Res Part F Traffic Psychol Behav 2018; 55: 262-271. Available from: https://www.sciencedirect.com/ science/article/abs/pii/S1369847817301523 [DOI: 10.1016/J.TRF.2018.03.003/ Google Scholar].

14. Taubman - Ben-Ari O, Kaplan S, Lotan T, Prato CG. Parents' and peers' contribution to risky driving of male teen drivers. Accid Anal Prev 2015; 78: 81-86. [DOI: 10.1016/J.AAP.2015.02.020/ PubMed/ Google Scholar].

15. Skvirsky V, Ben-Ari OT, Greenbury TJ, Prato CG. Contributors to young drivers' driving styles - A comparison between Israel and Queensland. Accid Anal Prev 2017; 109: 47-54. [DOI: 10.1016/J.AAP.2017.08.031/ Google Scholar].

16. Taubman-Ben-Ari O. Parents' perceptions of the family climate for road safety. Accid Anal Prev 2015; 74: 157161. [DOI: 10.1016/J.AAP.2014.10.023/ PubMed/ Google Scholar].

17. Ahmad H, Naeem R, Feroze A, Zia N, Shakoor A, Khan UR et al. Teaching children road safety through storybooks: an approach to child health literacy in Pakistan. Available from: https://bmcpediatr.biomedcentral.com/ articles/10.1186/s12887-018-0982-5 [DOI: 10.1186/ s12887-018-0982-5/ PubMed/ Google Scholar].

18. Jacoby SF, Winston FK, Richmond TS. Road safety perspectives among employees of a multinational corporation in urban India: Local context for global injury prevention. Int J Inj Contr Saf Promot 2017; 24(4): 493-500. [DOI: 10.1080/17457300.2016.1278235/ PubMed/ Google Scholar]. 